\title{
Fractional Snow Cover Estimation in Tibetan Plateau Using MODIS and ASTER
}

\author{
Xu Lina ${ }^{1}$ Shi Jiancheng ${ }^{1,2}$ Zhang Hongen ${ }^{1}$ Wu Shengli ${ }^{1}$ \\ 1 Institute of Remote Sensing Applications, Chinese Academy of Sciences Beijing, 100101 \\ P.O.Box:9718, Institute of Remote Sensing Applications, CAS, 3-3 Dadun Rd.,Chaoyang District, \\ Beijing Tel: 086-10-64854300-8036 Email: xln@mail.tsinghua.edu.cn \\ 2 Institute for Computational Earth System Science (ICESS) \\ University of Californian, Santa Barbara, CA 93106, USA
}

\begin{abstract}
Seasonal snow cover plays a significant role in regional, large even global scale climate processes, hydrological cycle and surface thermal balance processes. MODIS snow cover methods provide an operational model for mapping each pixel into snow or no-snow by using a normalized difference snow Index (NDSI) and its threshold test. But they cannot provide the fractional snow cover information. This paper presents an automated snow-mapping technique at sub-pixel resolution in Tibetan Plateau based on MODIS normalized difference snow fraction and normalized difference Vegetation fraction. This paper presents an automated snow-mapping technique at sub-pixel resolution based on MODIS normalized difference snow Index (NDSI) and normalized Difference Vegetation Index(NDVI) in order to avoid overestimations due to vegetation cover. And it takes the ASTER data as ground true data to verified this method.
\end{abstract}

Keywords-MODIS, ASTER, sub pixel snow mapping, Tibetan plateau

\section{INTRODUCTION}

Snow cover can play either a direct role, such as when estimating water capacity by melting, or indirectly such as when estimating surface thermal balance. Moreover, snow cover is an important input parameter for the hydrologic water. The Tibetan Plateau is the most sensitive area in the world to hydrological cycle and climatic change. Traditional in situ surveying and mapping cannot provide enough large-scale snow cover information; in addition it will take much time and money, sometimes even dangerous. Remote sensing is the only practical means for mapping snow cover. Due to a low reflectance of snow in the near infrared and a high reflectance in the visible, using NDSI can identify the snow cover from the other surfaces. MODIS snow cover methods (Hall, 1995) provide an operational model for mapping each pixel into snow or no-snow by using a normalized difference snow Index (NDSI) and its threshold test. But they cannot provide the fractional snow cover information. At present, it seems that spectral mixture method would have the best performance in estimating fractional snow cover within a pixel (Nolin, 1993; Rosenthal, 1996). But these approaches haven't been applied to a very large area such as the Tibetan Plateau. To provide accurate information about snow cover in Tibetan Plateau, more attention should be paid on fractional snow cover estimating.

This paper presents an automated snow-mapping technique at sub-pixel resolution based on MODIS normalized difference snow Index (NDSI) and normalized Difference Vegetation Index (NDVI) in order to avoid overestimations due to vegetation cover. And it takes the ASTER $15 \mathrm{~m}$ data as ground true data to calculate the percentage of snow cover for $500 \mathrm{~m}$ cells. We develop a link between a MODIS-NDSI corrected by NDVI and ASTER fractional snow cover. Case studies in Tibetan Plateau indicated that this new regression relationship could predict snow mapping in sub pixel resolution very accurately.

\section{METHOD}

MODIS snow cover methods provide an operational model for mapping each pixel into snow or no-snow by using a normalized difference snow Index (NDSI) and its threshold test.

The NDSI is calculated in (1) using the reflectance values. For 
the MODIS data,

$$
\text { NDSI }=\text { (band4-band6)/(band4+band6) }
$$

In the MODIS snow-mapping algorithm, snow is mapped in a pixel when the NDSI is $\geqslant 0.4$. A pixel that is approximately $50 \%$ or more covered by snow is considered snow-covered.

If there is enough information we can find from "NDSI", Salomonson et.al. (2004) tried to find the relationship between fractional snow cover and NDSI. In their approach a regression relationship between $500 \mathrm{~m}$ NDSI observation and the fractional snow cover coming from Landsat $30 \mathrm{~m}$ observation is set up. And it seems their relationship is robust and stable. But those linear relationships will be different in different area. In addition, this approach would be more fitted in non forest area.

In order to avoid overestimations due to vegetation cover this paper presents an automated snow-mapping technique at sub-pixel resolution based on MODIS normalized difference snow Index (NDSI) and normalized Difference Vegetation Index(NDVI). The NDVI is calculated in (2) using the reflectance values. For the MODIS data,

$$
\mathrm{NDVI}=(\text { band } 2-\text { band } 1) /(\text { band } 2+\text { band } 1)
$$

Three areas data corrected on the same day in the Tibetan Plateau were registered to a $500 \mathrm{~m}$ grid in a UTM project. The three areas covered several different areas in Tibetan Plateau were received by Dec. $7^{\text {th }}, 2000$, Sep. $30^{\text {th }}, 2000$ and Jun. $13^{\text {th }}$, 2001. The first two areas (Fig.1A, Fig.1B) were used to build the regression relationship. The third one (Fig.1C) were used in case studying.

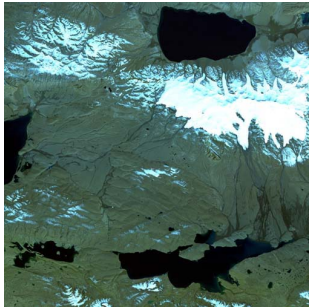

ASTER sub016

R: 3G:2 B:1

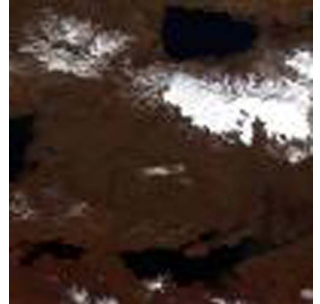

MODIS sub016

R: 1G:4 B:3

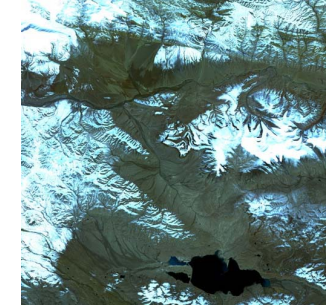

ASTER sub043

R: 3G:2 B:1

Figure.1B Area sub043

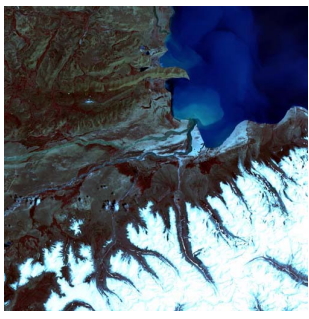

ASTER sub802158

R: 3G:2 B:1

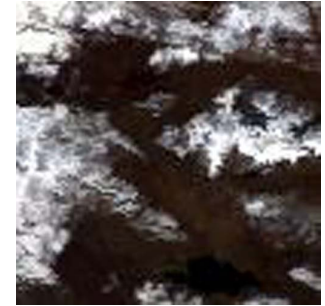

MODIS sub043

R: 1G:4 B:3

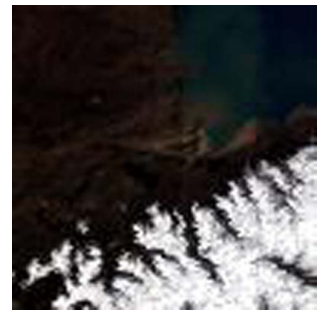

MODIS sub802158

R: 1G:4 B:3
Figure.1C Area sub802158

MODIS-NDSI was obtained from surface reflectivity of MDOIS observation in this paper. It takes the ASTER $15 \mathrm{~m}$ data as ground true data to calculate the percentage of snow cover for $500 \mathrm{~m}$ cells.

TABLE I. Regression Relationships Developed for the Two Areas Based on

\begin{tabular}{|c|c|c|}
\hline Areas and criteria & Subsets of pixels & FRA \& NDSI \\
\hline $\begin{array}{l}\text { Criteria } 1 \text { With snow } \\
(\text { FRA }>0) \\
\text { Sub016 }\end{array}$ & $\begin{array}{l}N=2625 \\
N=5679\end{array}$ & $\begin{array}{l}\text { NDSI*0.908+0.077 } \\
\text { NDSI }^{*} 0.860+0.117\end{array}$ \\
\hline 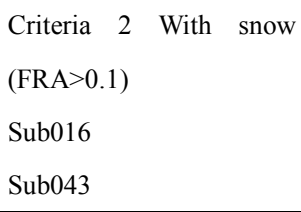 & $\begin{array}{l}N=1807 \\
N=4377\end{array}$ & $\begin{array}{l}\text { NDSI } * 0.961+0.069 \\
\text { NDSI } * 0.856+0.146\end{array}$ \\
\hline $\begin{array}{l}\text { Criteria } 3+\text { NDVI } \\
\text { With snow }(\mathrm{NDVI}<0 \text { \& } \\
\text { FRA }>0.1) \\
\text { Sub016 } \\
\text { Sub043 }\end{array}$ & $\begin{array}{l}N=1525 \\
N=3166\end{array}$ & $\begin{array}{l}\text { NDSI*1.224+0.119 } \\
\text { NDSI*1.275+0.139 }\end{array}$ \\
\hline
\end{tabular}
the Three Criteria 
So the regression relationship between NDSI and fractional snow cover based on the three criteria separately were set up for the two areas. TABLE I lists the regression relationship based on these conditions.

\section{RESULTS AND DISCUSSION}

The averaged method was used to test the stability and robustness of the regression relationships for the two areas. For the criteria 1 , the averaged regression relationship for area sub016 (NDSI*0.908+0.077) and area sub043 (NDSI*0.860+0.117) was gotten as (NDSI*0.884+0.097). For the criteria 2, the averaged relationship for area sub016 $(\mathrm{NDSI} * 0.961+0.069)$ and area sub043 (NDSI*0.856+0.146) was obtained as (NDSI*0.910+0.108). For the criteria 3, the averaged relationship for area sub016 (NDSI*1.224+0.119) and area sub043 (NDSI*1.275+0.139) was gotten as (NDSI*1.250+0.130).

Then the averaged relationship was tested on the third area (sub802158) and other areas of the Tibetan Plateau. Here, mean absolute error, rms error, correlation coefficient are separately calculated in (3), (4) and (5).

$$
\begin{aligned}
& \text { mean absolute error }=\frac{1}{n} \sum_{t=1}^{n}\left|\varepsilon_{t}\right| \\
& \text { rms error }=\sqrt{\frac{1}{n} \sum_{t=1}^{n} \varepsilon_{t}^{2}}
\end{aligned}
$$

$\varepsilon_{t}=\hat{X}_{t}-X_{t}, X_{t}$ is the true value of the image and $\hat{X}_{t}$ is the forecast of the value.

Correlation coefficient $=$

$$
\frac{\sum_{i=1}^{n}\left(x_{i}-\bar{x}\right)\left(y_{i}-\bar{y}\right)}{\sqrt{\sum_{i=1}^{n}\left(x_{i}-\bar{x}\right)^{2}} \sqrt{\sum_{i=1}^{n}\left(y_{i}-\bar{y}\right)^{2}}}
$$

The mean absolute error below 0.1 , and rms error could near to 0.1 . Among all the three criteria, the criteria 3 has the best performance. In the other areas of the Tibetan Plateau, the nearly same results could be obtained as area sub802158.
TABLE II Results showing the average relationship based on three criteria was testing on area sub802158.

\begin{tabular}{|l|l|l|l|l|}
\hline criteria & $\begin{array}{l}\text { Mean } \\
\text { snow } \\
\text { cover }\end{array}$ & $\begin{array}{l}\text { Mean absolute } \\
\text { error }\end{array}$ & rms error & $\begin{array}{l}\text { Correlation } \\
\text { coefficient }\end{array}$ \\
\hline 1 & 0.217 & 0.048 & 0.117 & 0.891 \\
\hline 2 & 0.217 & 0.039 & 0.126 & 0.909 \\
\hline 3 & 0.217 & 0.032 & 0.100 & 0.913 \\
\hline
\end{tabular}

In large scale area traditional in situ surveying and mapping cannot provide enough snow cover information while these fields always play an important role to the regional and global hydrological cycle and climatic change, such as the Tibetan Plateau. NDSI (normalized difference snow Index) can provide some useful information in estimating fractional snow cover. NDVI can help to avoid overestimations due to vegetation cover. This paper presents a linear regression method developed from MODIS NDSI corrected by NDVI and fractional snow cover in several areas of the Tibetan Plateau. It seems this approach can provide better estimation. More attention will be paid on how to improve the performance of the snow cover estimation within a pixel in Tibetan Plateau.

\section{REFERENCES}

[1] Hall, D.K., Riggs, G.A., \& Salomonson, V.V. (1995). Development of methods for mapping global snow cover using mederate resolution imaging spectroradiometer data. Remote Sensing of Environment, 54(2), pp. 127-140.

[2] Nolin, A.W., Dozier, J. and Mertes, L., 1993. Mapping alpine snow using a spectral mixture modeling technique, Ann. Glacier., 17, pp. 121-124.

[3] Rosenthal, W., and Dozier, J. 1996. Automated mapping of montane snow cover at a subpixel resolution from the Landsat Thematic Mapper, Water Resources Research., 32(1), pp. 115-130.

[4] Salomonson, A.A \& Appel I., 2004. Estimating fractional snow cover from MODIS using the normalized difference snow index, Remote Sensing of Environment, 89(2004), pp.351-360. 